JAMP: Jurnal Adminitrasi dan Manajemen Pendidikan

Volume 2 Nomor 1 Maret 2019, Hal : 10-16

Tersedia Online di http://journal2.um.ac.id/index.php/jamp/

ISSN 2615-8574 (online)

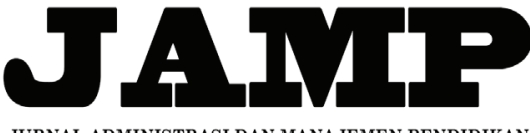

JURNAL ADMINISTRASI DAN MANAJEMEN PENDIDIKAN

\title{
HUBUNGAN MOTIVASI KERJA DENGAN KINERJA TENAGA KEPENDIDIKAN
}

\author{
Dahma Bagus Widodo \\ Ali Imron \\ Imron Arifin \\ E-mail: dahmabagus@gmail.com \\ Universitas Negeri Malang, Jl. Semarang No.5 Malang 65145
}

\begin{abstract}
This research aims to, (1) determine the motivation level to work of educational staff in the environment of faculties in State University of Malang, (2) determine the performance level of educational staff in the environment of faculties in State University of Malang, (3) determine the relationship of work motivation and performance of educational staff in the environment of faculties in State University of Malang. This research uses a quantitative approach with descriptive correlational design. The instrument of this research using a questionnaire respondents of the State University Malang environment. The analysis technique used in this research is descriptive analysis correlation. The results of this study indicate, (1) the motivation level to work of academic staff in the faculties of the State University Malang environment consisting of job satisfaction and job dissatisfaction hygienes motivators classified in the good category, (2) the performance level of educational staff in the faculties of the State University Malang environment consisting of quality, quantity, the necessary supervision, attendance, and conservation classified in the high category, (3) there is a significant positive relationship between work motivation and performance of educational staff in the environment of faculties in State University of Malang.
\end{abstract}

Keywors: work motivation, employee performance, educational staff, college

\begin{abstract}
Abstrak: Penelitian ini bertujuan untuk, (1) mengetahui tingkat motivasi kerja tenaga kependidikan di fakultas-fakultas lingkungan UM, (2) mengetahui tingkat kinerja tenaga kependidikan di fakultas-fakultas lingkungan UM, (3) mengetahui hubungan motivasi kerja dengan kinerja tenaga kependidikan di fakultas-fakultas lingkungan UM. Penelitian ini menggunakan pendekatan kuantitatif dengan rancangan penelitian deskriptif korelasional. Instrumen penelitian ini menggunakan angket dengan responden tenaga kependidikan di fakultas-fakultas lingkungan UM. Teknik analisis yang digunakan dalam penelitian ini yakni analisis deskriptif korelasi. Hasil penelitian ini menunjukkan, (1) tingkat motivasi kerja tenaga kependidikan di fakultas-fakultas lingkungan UM yang terdiri atas job satisfaction motivator dan job dissatisfaction hygienes tergolong dalam kategori baik, (2) tingkat kinerja tenaga kependidikan di fakultas-fakultas lingkungan UM yang terdiri atas kualitas, kuantitas, supervisi yang diperlukan, kehadiran, dan konservasi tergolong dalam kategori tinggi, (3) ada hubungan positif yang signifikan antara motivasi kerja dengan kinerja tenaga kependidikan di fakultas-fakultas lingkungan UM.
\end{abstract}

Kata kunci: Motivasi kerja, kinerja pegawai, tenaga kependidikan, perguruan tinggi

Manajemen kepegawaian dan sumber daya manusia merupakan suatu unsur penting bagi organisasi dalam mengatur, mengelola, dan memanfaatkan pegawai sehingga dapat berfungsi secara produktif dalam pencapaian tujuan organisasi. Peran dari sumber daya manusia dalam kinerja organisasi sangatlah penting, keputusan sumber daya manusia harus bisa meningkatkan efisiensi dan juga memberikan 
peningkatan hasil organisasi Imron (2018). Salah satu organisasi yang perlu adanya pengelolaan, pengaturan, dan pemanfaatan pegawai sehingga dapat berfungsi secara produktif yaitu perguruan tinggi. Perguruan tinggi adalah lembaga pendidikan formal, oleh sebab itu perguruan tinggi membutuhkan pengelolaan yang baik dalam bidang-bidang yang ada di dalamnya.

Perguruan tinggi memerlukan pengelolaan sumber daya manusia baik pendidik maupun tenaga kependidikan. Dalam Peraturan Menteri Pendidikan dan Kebudayaan Republik Indonesia nomor 71 tahun 2002 tentang Statuta Universitas Negeri Malang pasal 18 ayat 2 bahwa "rektor mempunyai tugas wewenang untuk membina dan mengembangkan pendidik dan tenaga kependidikan". "pembinaan dan pengembangan profesi dosen dilakukan melalui peningkatan kualifikasi akademik, kompetensi, dan jabatan fungsional" (pasal 96 ayat 2).

"Pembinaan dan pengembangan karier tenaga kependidikan dapat dilakukan dalam bentuk peningkatan kompetensi manajerial, peningkatan kompetensi teknis, kenaikan pangkat, promosi jabatan, dan atau peningkatan kualifikasi akademik" (pasal 96 ayat 4). Kompetensi teknis tenaga kependidikan diantaranya yaitu melakukan administrasi persuratan dan pengarsipan, mengadministrasikan kepegawaian, dan mengadministrasikan keuangan lembaga, seperti halnya tugas tenaga kependidikan yang ada di Universitas Negeri Malang. Melihat peran Universitas Negeri Malang sebagai organisasi yang besar dan melayani banyak orang, baik mahasiswa, dosen, alumni, maupun masyarakat. Sudah seharusnya Universitas Negeri Malang memiliki tenaga kependidikan yang mempunyai tingkat kinerja baik. Oleh karena itu tingkat kinerja tenaga kependidikan dituntut untuk terus meningkat.

Berbagai cara dalam meningkatkan kinerja tenaga kependidikan adalah dengan memberikan kompensasi terhadap pegawai yang memiliki tingkat kompensasi yang tinggi. Hal ini sesuai pendapat Imron (2018) ada banyak faktor yang mempengaruhi kinerja karyawan yaitu memotivasi, memberi kompensasi, komunikasi, kepribadian, lingkungan, kepemimpinan, dan insentif. Terdapat banyak faktor yang dapat mempengaruhi tingkat kinerja tenaga kependidikan salah satunya yaitu motivasi kerja. Adanya motivasi kerja yang tinggi maka otomatis seorang tenaga kependidikan akan memiliki kinerja yang baik pula.

Motivasi kerja adalah sesuatu yang menimbulkan dorongan atau semangat kerja (Yusuf dan Arif, 2015:264). Beberapa faktor yang dapat mempengaruhi motivasi kerja antara lain: atasan, kolega, sarana fisik, kebijaksanaan, peraturan, imbalan jasa uang dan non uang, jenis pekerjaan, dan tantangan. Perilaku tersebut akan mendorong tindakan aktivitas keseharian dari seseorang, sehingga hal ini dapat mempengaruhi motivasi seorang tenaga kependidikan.

\section{METODE}

Penelitian ini menggunakan pendekatan kuantitatif dengan rancangan penelitian deskriptif korelasional. Penelitian kuantitatif menurut Kasiram (2008:149) proses dalam menemukan pengetahuan berupa data dan menggunakan angka sebagai alat menganalisis. Dalam penelitian ini bersifat deskriptif sebab dapat menggambarkan mengenai variabel yang diteliti, bersifat korelasional sebab dapat mengetahui ada tidaknya hubungan antar dua variabel atau lebih. Hubungan antar variabel dapat dilihat pada gambar 1 .

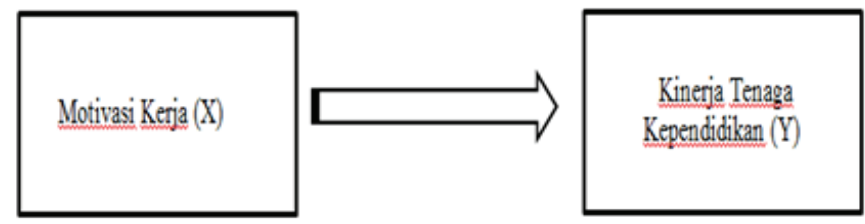

Gambar 1 Hubungan antar Variabel

Penelitian ini menggukan instrument penelitian berupa angket dengan responden tenaga kependidikan di fakultas-fakultas lingkungan UM. Jumlah populasi yang diteliti sebanyak 258 orang tenaga kependidikan, selanjutnya dalam pengambilan sampel penelitian ini menggunakan proportional random sampling dengan menggunakan rumus formula Slovin, yang diperoleh sampel sebanyak 161 
tenaga kependidikan. Teknik analisis deskriptif dan korelasi digunakan dalam penelitian ini. Dalam melakukan analisis data penelitian ini menggunakan bantuan Statistical Package for Social Science for Windows versi 20.0.

\section{HASIL}

\section{Motivasi Kerja}

Tingkat motivasi kerja di fakultas-fakultas lingkungan UM tergolong dalam kategori sangat tinggi sebesar $30.43 \%$. Tergolong dalam kategori tinggi sebesar $62.73 \%$. Tergolong dalam kategori sedang $4.35 \%$. Tergolong dalam kategori rendah sebesar $2.48 \%$. Sementara tergolong dalam kategori sangat rendah sebesar $0 \%$. Berdasarkan analisis data dapat disimpulkan, bahwa persentase tingkat motivasi kerja tenaga kependidikan di fakultas-fakultas lingkungan UM dalam kategori 'tinggi', yakni sebesar $62.73 \%$. Hasil penelitian tersebut merupakan kumpulan dari sub-variabel penelitian yang meliputi job satisfaction motivator dan job dissatisfaction hygienes.

Hasil dari kumpulan sub-variabel dapat disajikan sebagai berikut. Berdasarkan analisis data dapat disimpulkan, bahwa persentase tingkat job satisfaction motivator tenaga kependidikan di fakultas-fakultas lingkungan UM dalam kategori 'tinggi', yakni sebesar $73.91 \%$. Persentase tingkat job dissatisfaction hygienes tenaga kependidikan di fakultas-fakultas lingkungan UM dalam kategori 'tinggi', yakni sebesar $63.98 \%$.

\section{Kinerja Tenaga Kependidikan}

Tingkat kinerja tenaga kependidikan di fakultas-fakultas lingkungan UM tergolong dalam kategori sangat baik sebesar $32.30 \%$. Tergolong dalam kategori baik sebesar $65.22 \%$. Tergolong dalam kategori sedang $0 \%$. Tergolong dalam kategori tidak baik sebesar $2.48 \%$. Sementara tergolong dalam kategori sangat tidak baik sebesar $0 \%$. Berdasarkan analisis data dapat disimpulkan, bahwa persentase kinerja tenaga kependidikan di fakultas-fakultas lingkungan UM dalam kategori 'baik', yakni sebesar $65.22 \%$. Hasil penelitian tersebut merupakan kumpulan dari sub-variabel penelitian yang meliputi kualitas pekerjaan, kuantitas pekerjaan, supervisi yang diperlukan, kehadiran, dan konservasi. Hasil dari kumpulan sub-variabel dapat disajikan sebagai berikut.

Berdasarkan analisis data dapat disimpulkan, bahwa persentase tingkat persentase kualitas tenaga kependidikan di fakultas-fakultas lingkungan UM dalam kategori 'baik', yakni sebesar $64.60 \%$. Tingkat persentase kuantitas tenaga kependidikan di fakultas-fakultas lingkungan UM dalam kategori 'baik', yakni sebesar 58.39 \%. Tingkat persentase supervisi yang diperlukan untuk tenaga kependidikan di fakultas-fakultas lingkungan UM dalam kategori 'baik', yakni sebesar $70.19 \%$. Tingkat persentase kehadiran dalam bekerja tenaga kependidikan di fakultas-fakultas lingkungan UM dalam kategori 'baik', yakni sebesar $55.90 \%$. Tingkat persentase konservasi tenaga kependidikan di fakultas-fakultas lingkungan UM dalam memelihara sarana dan prasarana dikategori 'baik', yakni sebesar $59.01 \%$.

\section{Hubungan Motivasi Kerja dengan Kinerja Tenaga Kependidikan}

Berdasarkan hasil perhitungan diperoleh rhitung sebesar 0.826 dengan angka probabilitas sebesar 0.000 pada taraf signifikansi $5 \%$ atau 0.05 dengan tanda ** (dua bintang) pada analisis korelasi Product Moment Pearson dengan menggunakan SPSS 20.0 for windows dan jumlah sampel sebanyak 161 responden tenaga kependidikan di fakultas-fakultas lingkungan UM. Dari hasil perhitungan tersebut didapat pengujian hipotesis pada tabel 1 .

Tabel 1 Pengujian Hipotesis

\begin{tabular}{llll}
\hline Hipotesis & Hasil Uji & Sign & Hasil Pengujian \\
\hline $\begin{array}{l}\text { H0: tidak ada hubungan antara motivasi kerja } \\
\text { dengan kinerja tenaga kependidikan. }\end{array}$ & 0.000 & 0.050 & H0 ditolak \\
\hline
\end{tabular}


Berdasarkan pengujian hipotesis pada tabel 1 dapat diketahui bahwa $\mathrm{H}_{0}$ ditolak, dengan demikian maka $\mathrm{H}_{\mathrm{a}}$ diterima yang berarti ada hubungan antara motivasi kerja dengan kinerja tenaga kependidikan di fakultas-fakultas lingkungan UM. Nilai signifikansi berdasarkan pada tabel 1 yang menunjukkan angka 0.000 artinya angka probabilitas $(\mathrm{SIG})<0.05$ terdapat hubungan antara kedua variabel yang signifikan, dalam hal ini menunjukan adanya hubungan yang signifikan antara dua variabel tersebut dan bersifat positif, yakni jika variabel motivasi kerja besar, maka variabel kinerja pegawai semakin besar pula.

\section{PEMBAHASAN}

\section{Motivasi Kerja}

Tingkat motivasi kerja tenaga kependidikan di fakultas-fakultas lingkungan Universitas Negeri Malang yang tergolong dalam kategori tinggi, menunjukkan bahwa pegawai di fakultas-fakultas lingkungan Universitas Negeri Malang memiliki motivasi kerja tinggi. Motivasi kerja yang tinggi merupakan wujud keseriusan seseorang dalam mengerahkan kemampuan dan keahliannya untuk melaksanakan pekerjaanya guna tercapainya tujuan. Senada dengan pendapat Siagian (2012:138) motivasi adalah daya pendorong yang mengakibatkan seseorang tenaga kerja mau dan rela untuk mengerahkan kemampuan dalam bentuk keahlian atau ketrampilan tenaga dan waktunya untuk melaksanakan berbagai kegiatan yang menjadi tanggungjawabnya dan mampu melaksanakan kewajibannya, dalam rangka pencapaian tujuan dan berbagai sasaran organisasi yang telah ditentukan sebelumnya.

Hasil pengolahan data mengenai faktor sesuatu yang dapat memotivasi (job satisfaction motivator) menunjukkan beberapa indikator yang dapat meningkatkan motivasi kerja tenaga kependidikan di fakultas-fakultas lingkungan UM menjadi tinggi. Hal ini dibuktikan dengan adanya 119 responden atau sebesar $73.91 \%$ menyatakan bahwa beberapa indikator seperti prestasi (achievement), pengakuan (recognition), pekerjaan itu sendiri (work it self), tanggung jawab (responsibility), dan kenaikan pangkat (advancement) mampu meningkatkan motivasi kerja tenaga kependidikan di fakultas-fakultas lingkungan Unversitas Negeri Malang. Sependapat dengan Herzberg (dalam Robbins, 2003:213) bahwa Faktor sesuatu yang dapat memotivasi. Faktor tersebut yaitu faktor prestasi (achievement), faktor pengakuan/penghargaan (recognition), faktor pekerjaan itu sendiri (work it self), faktor tanggung jawab (responsibility), dan kenaikan pangkat (advancement). Faktor tersebut penting untuk diperhatikan dalam peningkatan motivasi kerja pegawai.

Hasil pengolahan data mengenai job dissatisfaction hygienes tenaga kependidikan di fakultasfakultas lingkungan UM memiliki tingkat persetase kategori 'tinggi', yakni sebanyak 103 responden atau sebesar $63.98 \%$. Artinya kemampuan institusi dalam hal ini UM dalam mengurangi atau mengantisipasi faktor-faktor yang dapat membuat ketidak puasan kerja pegawai dalam kategori tinggi. Sebagaimana yang diungkapkan Herzberg (dalam Robbins, 2003:213) Faktor higienis ketidakpuasan kerja. Faktor ini yaitu dapat berupa kebijakan dan administrasi (policy and administration), supervisi (supevision), hubungan dengan supervisior (relation with supervisior), kondisi kerja (working condition), gaji (salary), hubungan dengan rekan kerja (relation with peers), kehidupan pribadi (personal life), hubungan dengan bawahan (relation with subordinate), status (status), keamanan kerja (job security), dan pertumbuhan pribadi (personal growth). Indikator di atas jika tidak diperhatikan oleh pimpinan institusi bisa menurunkan motivasi kerja pegawai, oleh karenanya pimpinan harus mengantisipasi atau memperbaiki faktor-faktor yang dapat menyebabkan ketidak puasan kerja.

\section{Kinerja Tenaga Kependidikan}

Tingkat kinerja tenaga kependidikan di fakultas-fakultas lingkungan di Universitas Negeri Malang menunjukkan hasil prestasi kerja yang baik dan berkualitas dengan menunjukkan integritas yang tinggi dalam menjalankan pekerjaannya sesuai dengan pendapat Mangkunegara (2015:67) bahwa terdapat faktor yang mempengaruhi kinerja pegawai faktor individu secara psikologis, yaitu individu yang mempunyai 
integritas yang tinggi antara fungsi psikis (rohani) dan fisiknya (jasmani). Apabila integritasnya tinggi, maka individu tersebut akan dapat lebih mudah dalam berkonsentrasi untuk melaksanakan tugasnya dengan baik dan maksimal. Berdasarkan hasil penelitian yang dilaksanakan, dapat disimpulkan bahwa kinerja yang ditunjukkan oleh tenaga kependidikan di fakultas-fakultas lingkungan Universitas Negeri Malang berjalan dengan baik dan benar, sehingga pencapaian tujuan organisasi berjalan sesuai dengan yang direncanakan.

Hasil pengolahan data mengenai kualitas pekerjaan tenaga kependidikan di fakultasfakultas lingkungan Universitas Negeri Malang dalam kategori 'baik', yakni sebanyak 104 responden atau sebesar $64.60 \%$. Dalam hal ini tenaga kependidikan di fakultas-fakultas lingkungan Universitas Negeri Malang dapat menghasilkan pekerjaan yang berkualitas dilihat dari kerapian hasil kerja, ketepatan hasil kerja, ketelitian hasil kerja, dan keterkaitan hasil. Hal ini sesuai dengan penelitian Wulandari (2016) pekerjaan yang diselesaiakan dengan memiliki kualitas yang baik yaitu hasil pekerjaan dalam keadaan rapi, bersih, cermat, dan dengan ketelitian. Tenaga kependidikan di fakultas-fakultas lingkungan Universitas Negeri Malang dalam melaksanakan tuganya telah memperhatikan kualitas hasil kerja yang dikerjakannya. Hal ini disebabkan tenaga kependidikan mengutamakan ketelitian dalam melakukan pekerjaan sehingga dapat menyelesaikan pekerjaan yang berkualitas tanpa harus mengabaikan volume pekerjaannya.

Hasil pengolahan data mengenai kuantitas pekerjaan tenaga kependidikan di fakultasfakultas lingkungan UM dalam kategori 'baik', yakni sebanyak 94 responden atau sebesar $58.39 \%$. Hal ini berarti tenaga kependidikan di fakultas-fakultas lingkungan Universitas Negeri Malang mampu menghasilkan pekerjaan sesuai dengan beban kerja yang didapatkan walaupun dengan volume pekerjaan yang besar hal ini sesuai dengan pendapat yang diungkap Hasibuan (2003:105) Kuantitas kerja merupakan volume kerja yang dihasilkan dibawah kondisi normal. Hal ini dapat dilihat dari banyaknya beban kerja dan hasil kerja tenaga kependidikan di fakultas-fakultas lingkungan UM. Maka dari itu tenaga kependidikan harus mampu menentukan dan mengatur prioritas pekerjaan sesuai dengan beban kerja yang didapatkan sehingga dapat menyelesaikan pekerjaan sesuai dengan beban kerja dan jumlah output pekerjaan yang besar.

Hasil pengolahan data mengenai supervisi yang diperlukan untuk tenaga kependidikan di fakultasfakultas lingkungan Universitas Negeri Malang dalam kategori ‘baik', yakni sebanyak 113 responden atau sebesar $70.19 \%$. Hal ini menunjukkan bahwa tugas dari pimpinan di unit tenaga kependidikan di fakultas-fakultas lingkungan UM baik dengan telah membantu atau memotivasi pegawai agar pekerjaan mereka berjalan efektif guna mencapai tujuan yang dicapai. Hal tersebut sesuai dengan penelitian Zulkarnain (2012) seorang pemimpin relationshiporiented menitikberatkan kepemimpinannya pada bermacam usaha memotivasi kelompok untuk menerima apa yang telah digariskan sebagai tujuan kelompok dan memotivasi mereka guna bekerja mencapai tujuan. Hal ini dapat dilihat dari tugas seorang pimpinan tenaga kepegawaian di fakultas-fakultas lingkungan UM dalam memotivasi dan mengarahkan para pegawainya supaya dapat berusaha meningkatkan potensi kinerja dan kreatifitas dalam dirinya.

Hasil pengolahan data mengenai kehadiran dalam bekerja tenaga kependidikan di fakultas-fakultas lingkungan UM dalam kategori 'baik', yakni sebanyak 90 responden atau sebesar 55.90 \%. Kehadiran dalam berkerja sendiri salah satunya berkaitan dengan pemanfaat waktu saat bekerja. Hal ini menunjukan jika tenanga kependidikan di fakultas-fakultas lingkungan UM dalam memanfaatkan waktu kerja tinggi dan mampu menyelesaikan tugas sesuai dengan yang diugkapkan Hasibuan (2003:105) Pemanfaatan waktu merupakan pengggunaan waktu yang disesuaikan dengan kebijakan organisasi yang ada agar pekerjaan yang telah terencana selesai tepat pada waktu. Tenaga kependidikan di fakultas-fakultas lingkungan UM dalam melaksanakan pekerjaan telah memperhatikan beberpa hal diantanya dalam ketepatan waktu penyelesaian tugas, disiplin waktu dan penggunaan waktu. Hal tersebut sangatlah penting dikarenakan tuntutan pekerjaan yang harus diselesaikan sesuai dengan waktu yang telah 
ditetapkan. Tenaga kependidikan yang tidak memperhatikan ke tiga hal tersebut dapat kesulitan dalam menyelesaikan tugasnya sesuai dengan deadline atau waktu yang ditetapkan.

Hasil pengolahan data mengenai konservasi tenaga kependidikan di fakultas-fakultas lingkungan Universitas Negeri Malang dalam memelihara sarana dan prasarana dikategori 'baik', yakni sebanyak 95 responden atau sebesar $59.01 \%$.Indikator konservasi adalah pemeliharan peralatan agar mencengah kerusakan yang terjadi pada sarana yang digunakan sebagai penunjang kinerja pegawai agar tujuan organisasi dapat tercapai. Sesuai penelitian Pahlevi (2016) dalam hal pemanfaatan sarana dan prasarana, harus mempertimbangkan hal-hal yakni tujuan yang akan dicapai, kesesuaian antar media yang akan digunakan dengan materi yang aka dibahas, tersedianya sarana dan prasarana penunjang, dan karakteristik. Dalam hal ini tenaga kependidikan di fakultas-fakultas lingkungan Universitas Negeri Malang memiliki tingkat konservasi pada pemeliharaan barang yang tinggi yaitu mereka memelihara peralatan kerja yang menunjang pekerjaan meraka. Sebab peralatan yang terpelihara dengan baik dapat meningkatkan kinerja mereka yang nantinya pekerjaan tersebut berjalan secara efektif dan efisien.

\section{Hubungan Motivasi Kerja dengan Kinerja Tenaga Kependidikan}

Berdasarkan uraian hasil penelitian yang dilakukan disimpulkan bahwa tenaga kependidikan yang mempunyai motivasi tinggi dapat mempengaruhi tingkat kinerja tenaga kependidikan tersebut. Jadi motivasi kerja seseorang dapat mempengaruhi usaha dalam mencapai tujuan menyelesaikan pekerjaannya. Dapat dilihat tenaga kependidikan di fakutas-fakultas lingkungan UM memiliki tingkat motivasi kerja yang tinggi, dengan adanya tingkat motivasi yang tinggi tersebut maka akan menghasilkan kinerja maupun hasil kerja yang baik dalam melaksanakan tugas kerja sesuai dengan tanggung jawab yang diberikan kepadanya. Hal ini sesuai dengan pendapat Wukir (2012:115) motivasi kerja merupakan proses menjelaskan intensitas, arah, dan ketekunan seseorang dalam berusaha mencapai tujuannya, motivasi kerja yang besar menghasilkan hasil kerja besar pula. Selain itu, hasil penelitian yang di lakukan di fakultas-fakultas lingkungan UM telah memperhatikan faktor-faktor yang dapat mendorong kinerja tenaga kependidikan menjadi lebih baik. Sesuai dengan pendapat Hasibuan (2016:94) faktorfaktor pengaruh kinerja adalah prestasi kerja merupakan gabungan dari ketiga faktor penting, yaitu kemampuan minat seseorang pekerja, kemampuan dan penerimaan atas penjelasan delegasi tugas, serta peran dan tingkat motivasi seorang pekerja. Jadi semakin tinggi faktor yang motivasi kerja tenaga kependidikan maka dapat mempengaruhi baiknya tingkat kinerja.

\section{KESIMPULAN}

Motivasi kerja tenaga kependidikan di fakultas-fakultas Universitas Negeri Malang termasuk dalam kriteria tinggi.Tingkat kinerja tenaga kependidikan di fakultas-fakultas Universitas Negeri Malang yang terdiri dari kualitas pekerjaan, kuantitas pekerjaan, supervisi yang diperlukan, kehadiran, dan konservasi termasuk dalam kriteria baik. Hasil penelitian menunjukkan, ada hubungan positif yang signifikan antara motivasi kerja dengan kinerja tenaga kependidikan di fakultas-fakultas lingkungan Universitas Negeri Malang. Hal ini jika motivasi kerja besar, maka kinerja pegawai semakin besar pula. 


\section{DAFTAR RUJUKAN}

Hasibuan, M.S.P. 2016. Manajemen Sumber Daya Manusia. Edisi Revisi. Jakarta: PT Bumi Aksara.

Hasibuan, M. S.P. 2003. Manajemen : Dasar, Pengertian, dan Masalah (Edisi Revisi). Jakarta : Bumi Aksara.

Imron, A., Hasmin, \& Gunawan. 2018. Pengaruh Disiplin Dan Lingkungan Kerja Terhadap Kinerja Melalui Kemampuan Kerja Pegawai Kantor Unit Penyelenggara Pelabuhan Garongkong Kabupaten Barru. YUME: Journal of Management, 1(3), 124-137. Dari https://www.journal.stieamkop.ac.id/index.php/yume/article/ view/329/164.

Kasiram, Moh. 2008. Metodologi Penelitian. Malang: Universitas Islam Negeri Malang Pers.

Mangkunegara, A.P. 2015. Evaluasi Kinerja SDM (Redaksi Refika, Ed). Bandung: PT Refika Aditama.

Peraturan Menteri Pendidikan dan Kebudayaan Republik Indonesia nomor 71 tahun 2012 tentang Statuta Universitas Negeri Malang. (Online), (http://www.um.ac.id/data/download/ file64B5292334AF9E66827A4927A2165D73.pdf), diakses 17 Juli 2018.

Pahlevi, R., Imron, A., \& Kusumaningrum,D.E. 2016. Manajemen Sarana Dan Prasarana Untuk Meningkatkan Mutu Pembelajaran. Jurnal Manajemen Pendidikan, 25(1), 88-94. Dari http://ap.fip.um.ac.id/wp-content/ uploads/2015/05/12-Reza-Pahlevi.pdf.

Robbins, S.P. 2003. Perilaku Organisasi. Terjemahan Tim Indeks. Jakarta: Indeks Kelompok Gramedia.

Sondang, P. Siagian. 2012. Teori Motivasi dan Aplikasinya. Jakarta: PT Rineka Cipta.

Wukir. 2013. Manajemen Sumber Daya Manusia dalam Organisasi Sekolah. Yogyakarta: Multi Pers.

Wulandari,A. \& Arifin, I. 2016. Intensitas Komunikasi, Motivasi Kerja, dan Kinerja Tenaga Kependidikan. Jurnal Manajemen Pendidikan, 25(2), 185-190. Dari http://ap.fip.um.ac.id/wp-content/uploads/2017/01/JMP-EdisiSeptember-2016-vol-25-no-2-sep-2016.pdf\#page=68.

Yusuf, B. \& Arif, M.N.R. 2015. Manajemen Sumber Daya Manusia di Lembaga Keuangan Syariah. Jakarta: PT Raja Grafindo Persada.

Zulkarnain, W. Gaya Kepemimpinan Managerial Grid Kepala Sekolah Dasar. Jurnal Manajemen Pendidikan, 23(6), 497-503. Dari http://ap.fip.um.ac.id/wp-content/uploads/2015/05/volume-23-no.-614-21.pdf. 